\title{
Gram per Cage per Week
}

National Cancer Institute

\section{Source}

National Cancer Institute. Gram per Cage per Week. NCI Thesaurus. Code C73718.

A dose calculation unit expressed in gram(s) per cage per period of time equal to seven days. 